\title{
Del "Che" a Perón: en torno a la "peronización" de las Fuerzas Armadas Revolucionarias (FAR)
}

\author{
Carlos Ignacio Custer \\ UNSAM - Conicet \\ carlosignaciocuster@hotmail.com
}

El propósito de este trabajo es analizar algunos aspectos que consideramos claves en el proceso de "peronización" de las Fuerzas Armadas Revolucionarias (FAR), o como definió en sus propios términos la organización: la asunción del peronismo como su identidad política. Consideramos que las FAR revisten una peculiar relevancia en el sentido de evidenciar en su trayectoria fenómenos de mayor alcance que fueron característicos de los convulsionados años en el tránsito de las décadas del 60 a los 70, como la radicalización política de amplios sectores juveniles (principalmente estudiantiles y pertenecientes a los estratos medios) y la concomitante "peronización" de gran parte de ellos que llevó a estructurar un polo de comunicación y atracción de militantes de diversos orígenes que buscaban algún tipo de sintesis entre marxismo, nacionalismo y peronismo. Las FAR constituyen un ejemplo de ambos fenómenos, si bien en este estudio focalizaremos el análisis en el segundo de ellos, buscando desentrañar los elementos que explican el rápido proceso de "peronización" de la organización al poco tiempo de darse a conocer públicamente en julio de 1970.

Sobre la temática abordada, en el conjunto de la vasta bibliografia dedicada a los procesos de radicalización política en Argentina durante los 70, hasta hace poco solo se contaban algunas referencias fragmentarias en testimonios de militantes y trabajos que mencionaban de modo no acabado la trayectoria politica de las FAR. González Canosa (2012; 2013) es quien en un reciente estudio ha destacado algunos aspectos relevantes sobre los debates que llevaron a las FAR a emprender el camino de la "peronización", enfatizando ideas que desarrollara previamente en su tesis doctoral dedicada al itinerario político-ideológico de la organización, desde sus antecedentes más remotos durante los 60 hasta la campaña electoral de 1972. La referencia a la autora teniendo en cuenta el valioso aporte realizado es ineludible a la hora de encarar

(Archivos, año V, $\mathrm{n}^{\circ}$ 9, septiembre de 2016, pp. 77-96) 
un estudio sobre las FAR, aunque en relación a la "peronización" de la organización nos parece pertinente extender el análisis abarcando la fusión con Montoneros (octubre de 1973) para así dar cuenta de un modo exhaustivo de dicho proceso y comprender el decurso que terminó por poner fin a su existencia, lo que constituye una línea de investigación en proceso.

Para abordar nuestro objeto nos parece pertinente organizar la exposición del análisis propuesto en tres partes. En la primera, teniendo en cuenta el intento frustrado de sumarse al proyecto de Guevara por parte de militantes argentinos, consideraremos la tentativa abortada de relanzar el Ejército de Liberación Nacional (ELN) bajo el liderazgo de Guido "Inti" Peredo, que provocó que algunos de aquellos militantes confluyeran para conformar una nueva organización que, después de realizar una serie de redefiniciones estratégicas, terminó emprendiendo la lucha armada urbana con un enfoque nacional. En la segunda, explicaremos cómo esa nueva estrategia llevó a un rápido proceso de "peronización" que culminó luego de que las FAR se dieran a conocer públicamente y que al calor de las influencias políticas del momento implicaron un creciente acercamiento con las demás organizaciones político-militares peronistas y el primer intento de unificación frustrado de las mismas bajo la sigla de Organizaciones Armadas Peronistas (OAP). En la tercera, analizaremos la nueva posición asumida por las FAR y la vertiginosa aceleración de los tiempos políticos que las condujeron a emprender la fusión con Montoneros.

\section{Siguiendo las huellas del "Che": la experiencia del ELN y redefiniciones politicas, 1966-1969}

Los militantes que confluyeron y terminaron por formar las FAR convirtiéndose en sus principales líderes participaron con anterioridad en otras organizaciones políticas, ${ }^{1}$ de las que se desprendieron para intentar sumarse al proyecto encabezado por Guevara en Bolivia. El contexto

\footnotetext{
1. Algunos militaron en el Movimiento de Izquierda Revolucionario-Praxis liderado por Silvio Frondizi y luego constituyeron el Tercer Movimiento Histórico. El líder de este primer grupo terminó siendo Arturo Lewinger y en su seno también militaba su hermano Jorge Omar. Un grupo mayor en número provenía de la Federación Juvenil Comunista y del Partido Comunista (PC) que antes de confluir en la formación de las FAR participaron en diferentes agrupamientos, como Vanguardia Revolucionaria y el Sindicato de Prensa de la Capital Federal, entre otros. En este grupo militaron Oscar Terán, Eduardo Jozami (quienes al regreso de la experiencia cubana se separarian y conformarian otra organización: los Comandos Populares de Liberación), Carlos Olmedo y Roberto Quieto (quienes serian sucesivamente los dos líderes máximos de las FAR).
} 
imperante a partir del 29 de junio de 1966, con el gobierno militar que instaura la Revolución Argentina, operó como un factor decisivo para esos militantes a la hora de emprender el camino de la lucha armada, al barrer con toda posibilidad de actividad política legal y poniendo en el centro de la cuestión la necesidad de asumir una práctica armada frente a una dictadura que se presentaba destinada a gobernar sin plazos y por un largo lapso de tiempo. ${ }^{2}$

Es así que a mediados de 1966, los dos grupos de militantes argentinos referidos, de manera independiente y a través de contactos que tenían vinculación directa con funcionarios cubanos, emprenden el viaje a Cuba. Al momento de tomar dicha decisión, el conocimiento que poseian los militantes sobre el plan del que pasaban a formar parte era escaso, por no decir nulo. De las entrevistas efectuadas el hecho de participar de un movimiento liderado por el "Che" y el prestigio de contar con el apoyo del gobierno cubano eran los únicos aspectos conocidos del proyecto y los que facilitaron el compromiso de los militantes argentinos. ${ }^{3}$

La idea pergeñada por Guevara, luego del fracaso de la guerrilla en el Congo, era precisamente establecer en América Latina las bases del segundo y/o tercer Vietnam en el mundo. Bolivia era visto como el centro de operaciones de la futura guerrilla latinoamericana en el cual, luego de que se estableciera el primer foco revolucionario en dicho país, diversos contingentes de militantes de distintos países de América Latina se foguearian en combate para luego retornar a sus patrias de origen constituyendo los núcleos de las futuras columnas guerrilleras que pasarian a establecer nuevos frentes en los países vecinos extendiendo la revolución al resto del continente. En este planteo, la guerrilla que se proponía establecer Guevara en América Latina estaba pensada como de indole esencialmente rural y con un carácter marcadamente continentalista (Guevara, 1973a, 1973b).

Dentro de esta estrategia deben entenderse la formación militar de militantes de diversas nacionalidades entrenados durante los años 1966 y 1967 con el objetivo de sumarse al proyecto revolucionario liderado por Guevara. Con ese propósito varios grupos de un número muy reducido de militantes argentinos, entre los que se cuentan los dos grupos precursores de las FAR ya mencionados, emprendieron el viaje hacia la isla caribeña para recibir instrucción militar. Cano (2011) hace un recuento exhaustivo de los diversos grupos que recibieron instrucción en Cuba en esos dos años calculando que sobrepasaron numéricamente el centenar de militantes.

2. Entrevistas a Eduardo Jozami (Archivo Oral Memoria Abierta, en adelante AOMA, 2002), Oscar Terán (AOMA, 2005) y del autor a Jorge Omar Lewinger (2012).

3. Idem. 
El influjo de la persona del "Che" sin dudas operó como un efecto amalgamador de los diversos grupos de militantes argentinos que fluian hacía la isla, cuyos orígenes y trayectorias eran disimiles. En parte ello explica que luego de la muerte del "Che", acontecida en octubre de 1967, la mayoria de los grupos hayan proseguido su militancia por sendas diferentes. A partir de entonces, el gobierno cubano comienza a reconsiderar su propósito de exportar le revolución y la conveniencia de reorientar su política exterior de modo convergente con la politica de coexistencia pacífica Este-Oeste pregonada por la Unión Soviética (Furtak, 1985: 351-353).

Es así que, a fines de 1967 y principios de 1968, los grupos de argentinos regresan a Argentina y comienzan a debatir sobre cómo continuar con sus planes de impulsar la lucha armada, al tiempo que la guerrilla en Bolivia se reorganizaba bajo el liderazgo de "Inti" Peredo, boliviano sobreviviente del ELN original, contando con limitado apoyo cubano y concitando la adhesión de algunos militantes argentinos -entre los que se cuentan varios de los que luego formaron las FAR- con el objetivo de conformar un núcleo de apoyo local al frente boliviano (Rodríguez Ostria, 2006: 24).

Analizando el único documento del ELN argentino de que se tiene conocimiento, son sorprendentes las continuidades existentes con el proyecto original ideado por Guevara, así como también ciertos deslizamientos que de algún modo avizoran futuros cambios. La necesidad de un foco guerrillero rural y la continentalización de la lucha armada son mantenidas, pero la importancia de la red urbana clandestina es realzada mientras se sostiene la posibilidad de que los enfrentamientos puedan iniciarse a nivel local y de forma independiente. Como dice expresamente el documento, el doble objetivo es "contribuir al desarrollo de la guerrilla en Bolivia y crear las condiciones para la instalación de un foco guerrillero en la Argentina". ${ }^{4}$

Sin embargo, el intento de vincularse con el ELN boliviano dura poco, confirmándose la línea de constituir una organización revolucionaria que actuase de modo independiente en el país. Con posterioridad, la muerte de "Inti" en septiembre de 1969 y sucesivos descalabros abortan provisoriamente el intento de reconstituir el ELN, aunque éste es finalmente relanzado por su hermano Osvaldo "Chato" Peredo, operando en las montañas entre julio y noviembre de 1970 para ser definitivamente desarticulado, en momentos en que las FAR ya habian salido a la luz pública y no mantenian ninguna relación con el ELN (Rodríguez Ostria, 2006: 215-227, 540-546)

4. ELN, "Tareas para la implementación de un frente guerrillero en la Argentina", Archivo ex DIPBA, Legajo ${ }^{\circ} 110$. 
Hay que destacar que mientras los militantes argentinos estuvieron ligados al proyecto del ELN, tanto bajo el liderazgo del "Che" como durante el intento de relanzarlo del "Inti", y pese a las diferencias que emergieron, la cuestión del peronismo no fue un tema de discusión y no merecía ninguna atención a la hora de delinear y llevar a cabo la estrategia tendiente a impulsar el proceso revolucionario. Esto es avalado por varios testimonios de militantes ${ }^{5}$ y también por la mirada retrospectiva de las FAR sobre aquellos momentos, que poco tiempo después no dudaron en autocalificarse como una "pequeña patrulla perdida en el espacio de la lucha de clases". ${ }^{6}$

Antes del desmembramiento definitivo del ELN, entre los argentinos se generan una serie de discusiones que llevaron a dichos militantes a repensar los postulados ideológicos y políticos de su estrategia de lucha armada. Retrospectivamente las FAR reconocieron ciertas divergencias que mantuvieron con la dirección boliviana del ELN en relación al liderazgo exclusivo que pretendía aquella sobre el movimiento, posiblemente acentuadas ante el evidente proceso de "nacionalización" de la guerrilla y la centralidad que adquirian las acciones urbanas, transformaciones que fueron delineando una nueva estrategia. Ese doble proceso fue sin dudas alimentado por varios factores, entre los que hay que destacar el estallido de conflictividad social que se dio en el país a partir de 1969 luego del Cordobazo y que convenció a numerosas organizaciones armadas revolucionarias de la combatividad de la clase obrera argentina, la guerrilla urbana con resonante éxito que por ese entonces emprendió el Movimiento de Liberación Nacional - Tupamaros en Uruguay y los numerosos descalabros que sufrieron en varios puntos de América Latina los focos guerrilleros de carácter rural implantados durante los años $60{ }^{7}$

Estos fenómenos influyeron no solo en las FAR, sino también en el resto de las organizaciones armadas revolucionarias argentinas al momento de encarar el eje de discusión fundamental conformado por la definición de la vía efectiva a la revolución. Superada le etapa de ruptura con los planteos "reformistas" e "insurreccionalistas" considerados "oportunistas" y de mero "verbalismo revolucionario", la disyuntiva se planteaba para los grupos que pasaron a abrazar la lucha armada entre guardar una fidelidad absoluta con los lineamientos del foquismo cubano

5. Entrevistas a Jozami (2002), Lewinger (2012) y del autor a Juan Sasturain (2011).

6. FAR, "Reportaje a la guerrilla argentina. FAR: Los de Garin", Cristianismo y Revolución, $\mathrm{n}^{\circ} 28$, abril de 1971.

7. FAR, "Con el fusil del Che", en América Latina en armas, Ediciones M.A., Buenos Aires, 1971, y "Reportaje a la guerrilla argentina...". El impacto del Cordobazo y la influencia tupamara son reconocidas explícitamente por las propias FAR en dichos documentos. El primer texto fue editado en Argentina en enero de 1971, pero originalmente fue publicado en el periódico cubano Granma en diciembre de 1970. 
y desplegar una guerrilla en el ámbito rural o buscar impulsar una línea tendiente a instalar sus comandos en las ciudades. Esta última opción fue la que finalmente adoptaron casi exclusivamente las organizaciones armadas revolucionarias argentinas constituyendo a la lucha armada surgida en el país en un fenómeno esencialmente urbano. Para 1969, el grupo proveniente del PC (liderado por Olmedo) ya se había unido con el grupo liderado por Lewinger, a los que se les sumaron otros militantes (Lewinger y Chaves, 1999: 105-106), provenientes en su mayoria de las filas comunistas, conformando el núcleo de la futura organización que bajo la sigla de FAR se dio a conocer por medio de una resonante acción militar.

\section{De Garin al GAN: la asunción del peronismo y la polémica con el PRT-ERP, 1970-1971}

El 30 de julio de 1970 con la toma de la localidad bonaerense de Garin las FAR se dan a conocer públicamente. A raíz de dicha acción y por medio de un comunicado se presentaron ante la opinión pública definiéndose "impulsados por la necesidad de coronar con la victoria total el camino que inició nuestro pueblo el 17 de octubre de 1945". Al reconocimiento histórico otorgado a dicha fecha, se le sumaron la mención de otros fenómenos posteriores que evidencian tanto "la violencia oligárquica" como la "voluntad de rebeldía de nuestras masas" cuya expresión más radical se da en los sucesos acontecidos durante el Cordobazo y que constituyen un "mandato impostergable para los revolucionarios argentinos". Definen su accionar como tendiente a forjar el futuro ejército del pueblo que, al desarrollarse, iniciará una guerra popular "por la patria justa" y servirá para emprender el camino de la liberación de la explotación del hombre por el hombre. La única mención explícita a un personaje político es referida a Guevara quien es considerado como el "San Martín del siglo XX" y el comunicado finaliza con las dos proclamas que a partir de entonces pasaron a acompañar a todas las comunicaciones de la organización, una de autoría sanmartiniana ("Libres o muertos, jamás esclavos") y la otra popularizada por el "Che" ("Hasta la victoria siempre").

Al momento de su irrupción pública las FAR no asumen explícitamente ninguna filiación ideológica o política, más allá de las referencias implícitas que dejan entrever. Esta indefinición sin duda tuvo que ver con el estado en que se encontraba la naciente organización respecto a la delicada cuestión de definirse políticamente. Establecido el escenario urbano como el propicio para desplegar la lucha armada, la adopción de una estrategia nacional ponía en cuestión el posicionamiento de la organización en relación al movimiento peronista. Las menciones 
referidas al 17 de octubre, al derrocamiento del gobierno de Perón en 1955, los fusilamiento de 1956 y la anulación del resultado electoral de 1962 efectuadas en el comunicado denotan un claro acercamiento al peronismo. ${ }^{8}$ Esta actitud puede emparentarse también con la experiencia que tuvieron algunos de los fundadores de las FAR en las organizaciones donde militaron antes de intentar sumarse al proyecto del ELN. A la revalorización teórica del movimiento peronista efectuada por dichas organizaciones, se agregaron definiciones politicas afines a los sectores pertenecientes a la izquierda peronista y en algunos casos prácticas políticas en conjunto con militantes de sus filas (González Canosa, 2012: 53-59 y 125-129).

Hay que destacar que este proceso no estuvo exento de tensiones internas. González Canosa (2012: 99-101) entiende que el influjo personal y político de Guevara explica en gran medida que los grupos que constituyeron más tarde las FAR coincidieran en una experiencia tan disonante con la revalorización del peronismo que venían realizando. Sin embargo, dicha experiencia seguramente atrajo militantes con una formación de izquierda y seducidos por el foquismo, que no estuvieran dispuestos a transigir con posiciones contempladoras en relación al peronismo. Ya constituidas las FAR, la "voluntad peronizadora" de la dirección nacional de la organización fue progresivamente venciendo ciertas resistencias presentes entre algunos de sus militantes. González Canosa (2012: 136-138) alude a la resistencia de la regional de Córdoba a consumar la "peronización" motorizada por la regional Buenos Aires y aceptada por la de La Plata, que motivó que la conducción nacional de FAR buscara integrar un grupo tucumano identificado con el peronismo como la cuarta regional, tendiente a consolidar el predominio de la línea "peronizadora" por sobre la reticencia cordobesa. También del testimonio de Lewinger se destacan las discusiones que sostenian él y otro militante de las FAR con Olmedo, quien encabezaba personalmente los debates y la búsqueda de unificación de posiciones con los militantes reacios a asumir una identificación plena del peronismo (Lewinger y Chaves, 1999: 106). El proceso referido se extiende hasta por lo menos principios de 1971 y termina de consolidarse a lo largo del año, en el cual las FAR asumieron plenamente la identidad política peronista y formaron parte del primer intento fallido de confluencia con los otros grupos armados de dicha filiación (Descamisados, FAP y Montoneros) en el seno de las OAP.

Al momento de asumir el peronismo como su identidad política, las FAR elaboraron los principales documentos -de autoría del propio

8. FAR, “Comunicado n ${ }^{\circ}$ ", Cristianismo y Revolución, $n^{\circ} 25$, septiembre de 1970 [30 de Julio de 1970]. 
Olmedo- en los cuales sentaban las bases y los términos de la adscripción. En uno de ellos, se hace mención de que la dirección nacional de la organización se encontraba discutiendo la incorporación o no al movimiento peronista. ${ }^{9}$ Durante ese mismo año y de modo coincidente, las FAR pasaron a firmar sus comunicados con la proclama de "Por el retorno del pueblo con Perón al poder" acompañando a las dos que ya eran habituales. En febrero de 1971, Juan Domingo Perón escribe una carta célebre dirigida a "Los compañeros de la Juventud" elogiando el accionar de las filas juveniles (reconocidas como "juventud maravillosa"), exhortándolas a proseguir con la guerra revolucionaria entablada y reconociéndolas como "formaciones especiales" del movimiento encargadas de cumplir dicha tarea, hecho que seguramente facilitó la incorporación de las FAR al peronismo en ese momento (Baschetti, 1995: 137-141).

Las consideraciones que hacen las FAR sobre el peronismo en los documentos referidos, la manera de compatibilizar dicha identidad política con el marxismo en el marco de una estrategia revolucionaria, la visión del rol asignado a Perón y a la propia vanguardia, son de vital importancia para delinear los contornos de la peculiar concepción que guió a la organización y que explican los términos en que decidieron incorporarse al movimiento peronista. La revalorización del peronismo fue efectuada en virtud de considerarlo en el doble aspecto de ser la "experiencia revolucionaria de mayor nivel que se ha registrado en la Argentina a nivel de masas" y la "expresión política de la gran mayoría de la clase obrera". ${ }^{10}$ Esta evaluación apuntaba a realzar la importancia de la práctica de las masas peronistas en su lucha por medio de sus enfrentamientos, alianzas, victorias y derrotas, que al constituir la experiencia del pueblo, integraba a las FAR en ésta sin necesidad de efectuar ningún acto positivo, ya que ahora solo descubrian haber siempre formado parte de aquella. ${ }^{11}$ Además, y siguiendo su proceso nacionalizador, sostenían que el replanteo estratégico realizado los había llevado a considerar cuál era la fuerza capaz de protagonizar el proceso revolucionario en el país -la clase obrera- cuya identificación peronista expresaba a nivel político (peronismo-antiperonismo) la contradicción social a nivel estructural. ${ }^{12}$

Como se desprende de este último argumento, las FAR pasaron a definir su estrategia dentro de los lineamientos del nacionalismo revolucionario, considerando que la acción a desplegar implicaba enfrentar

9. FAR, "Con el fusil del Che".

10. Ídem.

11. FAR, "Reportaje a la guerrilla argentina...".

12. FAR, "13 Preguntas de la Brigada 'Jorge R. Masetti' de las FAL”, Archivo ex DIPBA, Legajo $n^{\circ} 641$ [octubre de 1971]. 
determinadas fuerzas sociales asentadas en un marco nacional, hecho que las llevó a revalorizar positivamente la experiencia peronista para identificarse y asumirla politicamente tanto en sus aciertos y logros como en sus limitaciones. Desarrollar los primeros y combatir para superarlas las segundas seria el único modo de fomentar la potencialidad revolucionaria que albergaba el peronismo. ${ }^{13}$ Esto, además de dotar de efectividad sus planteos revolucionarios, al servir de punto de acercamiento entre ciertos sectores políticos marxistas que en su proceso de radicalización abandonaban los planteos de la izquierda tradicional y las masas trabajadoras cuya identidad politica mayoritaria seguía siendo invariablemente peronista, permitía según las propias FAR rehuir cualquier tipo de táctica "entrista" en la medida que se realizaba por medio de una crítica y práctica revolucionaria explícita. Sin dudas, la propuesta elaborada por las FAR fue tributaria de algunas concepciones acuñadas por ciertos intelectuales que formaron parte de lo que fue llamado la izquierda nacional o el peronismo revolucionario, como Juan José Hernández Arregui y John William Cooke. ${ }^{14}$ Dichos autores, junto a otros como Jorge Abelardo Ramos y Rodolfo Puiggrós, buscaron plasmar en sus obras una concepción que sirviera de guía al accionar de los sectores combativos del peronismo para encauzar al movimiento por una senda revolucionaria.

Este intento de combinación de marxismo y peronismo fue efectuado por las FAR al considerar al primero como una herramienta de análisis y al segundo como la identidad política de la organización. La organización argumentó a la luz de los autores clásicos del marxismo que éste debía ser utilizado como una herramienta teórica al servicio de la liberación y no ser convertido en una "bandera política universal" opuesta a la ideología concreta de la fuerza social capaz de protagonizar el cambio revolucionario como hacian algunos grupos de izquierda. Según esta visión, la ideología era la conciencia que los hombres adquieren de su propia situación y cuya modificación más lenta que la de las estructuras socioeconómicas estaba en el origen de que muchos grupos de izquierda

\section{Idem.}

14. La influencia de las ideas de Hernández Arregui y Cooke son notables en la opción por el peronismo realizada por las FAR. Respecto del primero se destaca fundamentalmente el análisis histórico que hace sobre la formación de la conciencia nacional y la crítica a los partidos de la izquierda tradicional como ajenos y opuestos a dicho proceso (Hernández Arregui,1960: 9-11, 97-164). En cuanto a Cooke, sobresale su insistencia ante Perón para que definiese en el plano ideológico al peronismo como un movimiento de liberación nacional o partido de izquierda en sintonía con los procesos de liberación mundiales (Egipto, Argelia y fundamentalmente Cuba) y en el plano político estructurase una estrategia revolucionaria consecuente a tal fin (Perón y Cooke, 1972: 153-160, 173-175, 245-250). 
cayeran en el ideologismo de interpretar la realidad a partir de las ideas de los propios actores, hecho que los llevaba a rechazar el contraste evidenciado entre éstas respecto de sus conceptualizaciones abstractas, sin considerar el papel jugado por las clases o fuerzas sociales en el marco de las contradicciones de una formación social específica. ${ }^{15}$

Estas consideraciones motivaron una respuesta de un grupo de militantes del Ejército Revolucionario del Pueblo (ERP) centrada principalmente en defender el rol de las direcciones revolucionarias como transmisoras de la ideología marxista, condenar el carácter espontaneísta y contrarrevolucionario del peronismo que lo constituía en una ideologia burguesa deformada en oposición al carácter científico y revolucionario del marxismo y alertar sobre el posible retorno de Perón como factor de orden del sistema para calmar los impetus revolucionarios de las masas. ${ }^{16}$ En respuesta, en un documento firmado por el propio Olmedo, las FAR pretendieron plantear la apropiación del marxismo para demostrar la inconsistencia de los "marxistas a ultranza", ya que éstos no comprendían el desarrollo material de la historia cuando ésta contradecía sus construcciones mentales. Asimismo, sostenían que su posición era coherente con los planteos de Marx y Lenin sobre la aplicación de la teoría revolucionaria. Citaban que el fundador del socialismo científico se negó a ser considerado marxista absteniéndose de anteponer su visión teórica a la realidad concreta, siendo esta última siempre el punto de partida de sus análisis. En cuanto a Lenin se basaban en sus ideas respecto de la formación de la ideología para afirmar que si el peronismo pudiera ser considerado una ideología burguesa tal como afirmaban los militantes del ERP, eso solamente se debia a que la clase obrera argentina adoptó dicha ideología en la medida que el movimiento peronista fue el que expresó sus intereses reales y concretos en un grado acorde con su desarrollo histórico. ${ }^{17}$

El debate entablado con el PRT-ERP no solo adquirió el valor de un manual fundamental e iniciático para su militancia, sino que además ejerció su influjo sobre sectores radicalizados proclives a aceptar un mayor acercamiento al peronismo, dado que brindaba una argumentación más sofisticada sobre el tópico sintetizando en forma más elaborada la

15. FAR, "Reportaje a la guerrilla argentina...".

16. "Respuesta del ERP al reportaje de las FAR", Militancia Peronista para la Liberación, $\mathrm{n}^{\circ}$ 4, Buenos Aires, 5 de julio de 1973 [abril-mayo de 1971].

17. FAR, "Aporte al proceso de confrontación de posiciones y polémica pública que abordamos con el ERP. Respuesta elaborada por el compañero Olmedo", Militancia Peronista para la Liberación, n 4, Buenos Aires, 5 de julio de 1973 [escrito en 1971 con posterioridad a abril-mayo]. 
visión crítica que sostenían las organizaciones político-militares peronistas respecto de los planteos del PRT-ERP.

Para las FAR, el movimiento peronista expresaba la identidad y la acción de un conjunto de clases y sectores, de ahí el reconocimiento de su carácter policlasista, aunque su potencialidad revolucionaria residia en integrar a la mayoria de la clase obrera argentina y en el hecho de que de su seno surgian organizaciones conscientemente revolucionarias. ${ }^{18} \mathrm{Sin}$ embargo, el peronismo tenía un líder indiscutido, hecho que no podía ser desconocido por las FAR. Por aquel entonces la organización reconocía en la figura de Perón un "líder popular" que por medio de su reelaboración doctrinaria iba ajustando sus concepciones a las alteraciones que acontecian en la realidad nacional e internacional. ${ }^{19}$ Precisamente, una de las tareas era forjar una alternativa que permitiera al líder optar por los sectores revolucionarios y desechar a los elementos "traidores" y reformistas, iniciando el proceso de liberación acorde con el auge de masas y los procesos que se desarrollaban al calor del surgimiento de movimientos de liberación nacional en los países del Tercer Mundo. ${ }^{20}$

En relación a las diferentes posiciones de las organizaciones político-militares respecto del carácter atribuido al peronismo y a su líder, Lanusse (2005: 255-256) distingue tres y destaca al mismo tiempo que dificilmente se hayan podido dar en estado "puro" en algún momento preciso en el seno de alguna agrupación. En cuanto a la postura de las FAR de forjar una alternativa para que Perón pudiera optar por los sectores revolucionarios del movimiento, no estariamos frente a una posición "alternativista", tal como sí plantearon contemporáneamente las Fuerzas Armadas Peronistas (FAP) al momento de impulsar la construcción de su "Alternativa Independiente", luego de desechar su "movimientismo" primigenio. El "movimientismo" se caracterizaba por reconocer en el peronismo un movimiento revolucionario en su conjunto y un liderazgo revolucionario en la figura de Perón, postulando la necesidad de impulsar métodos combativos como modo de radicalizarlo y erradicar a los "traidores", quienes ante la dinámica de la lucha se verian obligados a sumarse al proceso o quedar de lado. El "alternativismo", en cambio, sostenía la necesidad de desarrollar una herramienta y una práctica política propia e independiente de los "burócratas" y "traidores" dado que la propia experiencia del peronismo evidenciaba que la burocracia por medio de sus estructuras siempre había terminado por imponerse y aplastar el impulso de los sectores revolucionarios. Manteniendo la identidad peronista y con una postura clasista, no reconocían abierta-

18. FAR, "Con el fusil del Che".

19. Entrevista a Lewinger (2012).

20. FAR, "Reportaje a la guerrilla argentina...". 
mente que dentro de su visión se desprendía la idea de Perón como un líder burgués. La posición de las FAR tal como analizamos anteriormente se situaba en una posición intermedia y asimilable al "tendencismo", en la medida que al mismo tiempo que suponía el reconocimiento de diferencias irreconciliables en el seno del movimiento peronista, le reconocían a éste una potencialidad revolucionaria que podia ser impulsada desde adentro del mismo.

Teniendo esta concepción del peronismo, las FAR consideraban a principios de 1971 que no existía una vanguardia en cuanto tal y que ésta estaba en proceso de construcción en la medida en que combatientes por medio de diversas organizaciones asumian la responsabilidad teórica y práctica de emprender la lucha armada que permitiría al pueblo encaminarse hacia el enfrentamiento directo por su liberación. Una guerra verdaderamente popular solo se produciría cuando la población comenzase progresivamente a apropiarse del método de lucha y las herramientas de conocimiento necesarias. Algo que consideraban solo lo podía definir el curso del proceso revolucionario y la acción de la propia clase obrera en su desarrollo, ante lo cual definian como única posición posible para una organización revolucionaria el estar junto a las fuerzas populares en dicha experiencia por medio de la práctica. ${ }^{21}$

Como destaca González Canosa (2012: 155-180; 2013), los posicionamientos de las FAR implicaron que la organización se involucrara en una disputa en dos frentes sobre la versión legítima tanto del marxismo como del peronismo, cuyos destinatarios centrales eran respectivamente los sectores de izquierda, a los que intentaban convencer de emprender el camino de la "peronización", y la militancia peronista, ante la cual buscaban presentarse como integrantes del movimiento. Esta doble dinámica los llevó a asumir una "posición bisagra" entre las organizaciones politico-militares peronistas (FAP y Montoneros, principalmente) y el Partido Revolucionario de los Trabajadores (PRT, partido político conductor del ERP) que, en virtud de sus planteos, ubicó a las FAR en una postura intermedia entre ambos polos (Caviasca, 2006: 11).

Por añadidura, la polémica entre las FAR y el PRT-ERP antes referida debe enmarcarse en los debates que comenzaron a surgir con fuerza entre las organizaciones armadas revolucionarias, en el seno de las mismas y también entre los sectores radicalizados respecto del peronismo a medida que la dictadura empezó a resquebrajarse luego del ascenso de la conflictividad social y política desatada a partir de 1969 . Dicha necesidad de definición respecto del peronismo se relaciona con un segundo eje fundamental que atravesó a todas las organizaciones y que estaba constituido por su efectiva vinculación con las masas 
y más específicamente por la relación que debian establecer entre la acción militar y la acción propiamente política por ellas desplegadas. Organizativamente, la construcción y accionar del aparato armado fue acompañada por la búsqueda de vincular agrupaciones políticas, sindicales, estudiantiles y barriales con la organización, ya sea por medio de la acción directa de células partidarias (PRT-ERP) ${ }^{22}$ o estructurando formas organizativas que operaban como nexo entre las primeras y la organización revolucionaria para impulsar el trabajo político al mismo tiempo que se resguardaba la seguridad de esta última, como fue el caso de las Unidades Básicas Revolucionarias en Montoneros y los Comandos de Apoyo en las FAR. ${ }^{23}$ Pero políticamente las organizaciones armadas revolucionarias enfrentaban una situación en la que la clase trabajadora y los sectores populares continuaban identificándose mayoritariamente con el peronismo y el influjo de Perón, aunque ausente, no podía soslayarse. Este fenómeno no puede circunscribirse solamente a las FAR, que por medio de la asunción del peronismo buscaron un "salto de claridad, alcance y eficacia" en su "relación política e ideológica con la clase obrera y las masas populares", ${ }^{24}$ ya que las (re)consideraciones acerca de dicho movimiento estuvieron presentes incluso en el seno de las organizaciones politico-militares peronistas (como las FAP) y en otras tantas organizaciones condujeron a fuertes tensiones internas (columnas de las Fuerzas Argentinas de Liberación [FAL], Comandos Populares de Liberación [CPL] y la Guerrilla del Ejército Libertador [GEL]) y a una escisión incluso en el PRT-ERP, con el surgimiento del ERP-22 de Agosto en 1973.

\section{Construyendo la alternativa revolucionaria: la consolidación de la "tendencia" y la fusión con Montoneros, 1972-1973}

La coyuntura de 1972 implicó algunas modificaciones que llevaron

22. En el caso del PRT, los militantes del partido formaban parte del ERP, participando en las acciones armadas del ejército, pero además desarrollando la actividad propiamente politica, ya sea individualmente o por medio de células partidarias en el ámbito de inserción de masas correspondiente.

23. La relación entre la acción propiamente política y la acción militar estaba primigeniamente pensada en las FAR por medio de la idea de "articulación", que suponía cierto grado de flexibilidad que compatibilizara la seguridad requerida por la acción clandestina con la apertura necesaria para desplegar acciones de masas asegurando la integralidad del militante revolucionario. Esta concepción fue dejándose de lado cuando la organización adoptó la estructura organizativa referida. Entrevista del autor a Manuel Cannizo (2013).

24. FAR, "13 preguntas de la Brigada...". 
a las FAR a reforzar sus posiciones adoptando una postura claramente "tendencista". La consolidación de la apertura politica desplegada por la dictadura militar a partir de ese año por medio del Gran Acuerdo Nacional (GAN), diseñado por Lanusse para condicionar la integración del peronismo con miras a una eventual convocatoria electoral, y la voluntad de Perón de intentar neutralizar la maniobra con el fin de viabilizar la participación electoral irrestricta del peronismo hicieron acuciante la necesidad de definiciones respecto del nuevo escenario imperante. A medida que el proceso se acelere y la Revolución Argentina entre en su etapa terminal, las disyuntivas van a terminar cerrándose y las opciones para las organizaciones armadas y los militantes revolucionarios parecieron polarizarse entre sumarse a la guerrilla no peronista (PRTERP) o pasar a conformar el polo revolucionario dentro del peronismo (Montoneros)..$^{25}$

Las FAR, por su parte, reorientaron su política con el objetivo de generar una "alternativa estratégica y organizativa revolucionaria peronista" para incorporar a la mayor cantidad de sectores combativos del movimiento ${ }^{26}$ frente a una situación donde la dictadura militar y el exilio de Perón daban paso a un inminente proceso electoral y a la posibilidad del retorno efectivo del líder. Ante dicha coyuntura, las FAR rechazaron de plano el GAN como maniobra "gatopardista" y "continuista" de las clases dominantes a fin de romper su aislamiento por medio del "retorno a las instituciones democráticas", pero aceptando (luego de que lo hiciera Montoneros) la participación en un eventual proceso electoral ante la convocatoria de Perón a constituir el Frente Cívico de Liberación Nacional (FRECILINA) como acción destinada a neutralizar los anhelos militares. Las FAR entendian que la salida electoral podía ser aceptada como una maniobra táctica a fin de mejorar las condiciones para el logro de sus objetivos estratégicos, y así podía aumentar las fuerzas propias y debilitar las fuerzas y planes de las clases dominantes, al mismo tiempo que intentaban convertirla en un elemento de concientización y al FRECILINA en un instrumento de lucha integral contra el sistema utilizándolo como medio de confluencia con todos los sectores peronistas empeñados en desarrollar una guerra de liberación.

25. Alrededor de 1973 las distintas columnas de las FAL se van disolviendo, integrándose según el caso al PRT-ERP, a Montoneros u a otras organizaciones menores. GEL se desintegra, incorporándose algunos de sus militantes al PRT-ERP y otros a FAR. Descamisados, FAR y CPL confluyen en Montoneros. De las FAP un sector importante se une a Montoneros, algunos militantes al PRT-ERP, mientras que el resto se mantiene en las FAP-Comando Nacional (siguiendo la linea referida de conformar la "Alternativa Independiente") o se disgrega.

26. FAR, "Sintesis del informe sobre el movimiento y la izquierda", Archivo ex DIPBA, Legajo $n^{\circ} 641$ [enero de 1972]. 
En esta circunstancia, consideraban prioritario avanzar en la fusión de las organizaciones armadas, fortalecer las relaciones con las "agrupaciones de base" y "comandos de apoyo" como nexos imprescindibles para el crecimiento de la opción revolucionaria e ir estableciendo formas organizativas "de transición" hacia el ejército del pueblo, elementos imprescindibles para desarrollar la etapa de "extensión de la guerra" que consideraban estar atravesando. ${ }^{27}$

Para fines de 1972 el acercamiento con Montoneros parece estar encaminado, si nos atenemos a lo expresado en un documento conjunto preparado por militantes de ambas organizaciones recluidos en la cárcel de Rawson y fechado en agosto del mismo año. Hay que tener en cuenta que en ese momento los dos principales líderes de las FAR (Quieto y Marcos Osatinsky) se encontraban presos en Rawson-Olmedo fue muerto en un operativo armado el 3 de noviembre de 1971 en la localidad cordobesa de Ferreyra- al igual que otro grupo de Montoneros de menor nivel jerárquico en su organización (liderado por Fernando Vaca Narvaja), junto con otros militantes sindicales y políticos revolucionarios. En dicho trabajo se hace un balance crítico de la experiencia politica de las OAP como "primera etapa en el proceso de fusión de las organizaciones armadas" y se manifiesta haber "dado un pequeño paso, como grupo de prisioneros de guerra hacia la fusión" entre ambas agrupaciones. Definían el proceso revolucionario a desarrollarse como de carácter nacional y social dada la estructura económica del país caracterizada como "capitalista monopólica dependiente del imperialismo" para lo cual consideraban al peronismo como la fuerza política con mayor capacidad para llevar adelante el proceso y el cual solo podría llevarse a cabo por medio de una "guerra popular prolongada". En el mismo documento conciben al movimiento peronista, cuya organicidad es asegurada por el liderazgo de Perón (relación líder-masas), como el eje central de un "Movimiento de Liberación Nacional" en desarrollo que en dicho proceso ve el surgimiento de una mayor claridad en los contenidos ideológicos y de formas superiores de lucha como es la organización político-militar articulada en la relación vanguardia-masas y que constituye el germen del futuro "Ejército Peronista Montonero" (EPM). Dicha concepción suponía que el liderazgo de Perón solo era apto para conducir el movimiento expresando el estado de conciencia alcanzado por el pueblo en ese momento, pero era incapaz de generar instancias superadoras que asegurasen en un futuro la toma efectiva del poder. Ello solamente sería posible por el surgimiento de una vanguardia reconocida por las masas y que en un

27. FAR, "Documento de actualización política", Archivo ex DIPBA, Legajo n 641 [septiembre de 1972] y "Opiniones sobre los problemas centrales de la guerra revolucionaria en esta etapa" (elaborado conjuntamente por prisioneros de FAR y Montoneros), Boletín n 4 [10 de Agosto de 1972]. 
plano superior de conciencia las movilizara y organizara dirigiendo el movimiento y desarrollando la "guerra popular prolongada". ${ }^{28}$

El documento referido resulta llamativo en la medida que define de modo tajante el rol revolucionario de la vanguardia y el carácter de "líder popular" asignado a Perón, teniendo en cuenta el "movimientismo" originario que caracterizaba a la organización Montoneros. Asimismo, marca una clara apropiación de terminologia y concepciones propias de otras experiencias de procesos de liberación nacional que se llevaron a cabo en el Tercer Mundo (Vietnam y Argelia, principalmente) y que tuvieron como primer modelo a la guerra de liberación china frente a la invasión japonesa (1937-1945). Las definiciones del país como capitalista dependiente del imperialismo, del peronismo como eje central de un futuro movimiento de liberación nacional y la necesidad de construir un ejército popular para liberar al país por medio de una guerra prolongada dan cuenta de dicha influencia y principalmente de la inspiración maoista de dichas nociones (Mao, 1972). Esta apropiación suponía un esfuerzo por aplicar categorias elaboradas en base a realidades politicas y sociales muy diferentes al contexto en que buscaron aplicarse, hecho que era considerado posible al asimilar a las Fuerzas Armadas como un ejército de ocupación que usurpaba el gobierno para sostener un régimen económico capitalista sujeto a los intereses del imperialismo norteamericano.

Como se desprende de lo expuesto, ambas organizaciones venían unificando concepciones y delineando una posición que desplegaron con fuerza durante la campaña electoral de 1973, aglutinando a numerosos sectores radicalizados que se incorporaban a las agrupaciones politicas que lideraban al calor del auge de la movilización política que se desplegó durante el ocaso de la Revolución Argentina, dando forma a lo que pasó a denominarse como la tendencia revolucionaria del peronismo o, más sucintamente, la "tendencia". Precisamente, Montoneros fue quien tuvo más éxito en este aspecto al organizar nuevas formas de encuadramiento centralizadas que concentraron ese influjo sometiéndolas a una firme dirección por parte de la organización. Primero fue la Juventud Peronista, para luego dar paso al establecimiento de los denominados "frentes de masas", con ámbitos más específicos de acción a lo largo de 1973. En ese crucial año, las FAR y Montoneros apoyaron al gobierno peronista de Héctor Cámpora, ocupando un papel de movilización y visibilización central durante la campaña electoral, aunque seguían sosteniendo la necesidad de construir poder popular y continuar con la formación del EPM como única manera de lograr la toma del poder económico y militar

28. FAR, "Opiniones sobre los problemas centrales...". 
garantizando el proceso de liberación nacional y popular, ${ }^{29}$ al mismo tiempo que aceleraban el proceso de fusión de ambas organizaciones, que se anunció oficialmente al momento de asumir Perón su tercer mandato como Presidente de la República, el 12 de octubre de 1973. A partir de allí se inició una nueva etapa signada por una creciente oposición entre el proyecto revolucionario de la organización Montoneros y el impulsado desde el gobierno por el viejo líder centrado en el pacto social y la búsqueda de pacificación del país, contradicción que terminó desembocando en el enfrentamiento directo y violento en el seno del propio peronismo.

\section{Reflexiones finales}

En este artículo hemos analizado los aspectos centrales de la "peronización" de las FAR. Dicho proceso, que consistió en un replanteo político para dotar de efectividad histórica a sus planteos revolucionarios al unir el único método científico de interpretación de la historia (el marxismo) con la única fuerza social capaz de asumirlo con verdadera eficacia subversiva (la clase obrera peronista), puede ser visto como un intento de reedición de anteriores experiencias o teorizaciones que intentaban vincular ambas tradiciones en el marco de una estrategia revolucionaria. La peculiar visión de las FAR, además se conjugó con la práctica concreta de la lucha armadas y la originaria concepción foquista que sin lugar a dudas incidieron en la forma en que la organización asumió sus nuevos planteamientos. Las FAR, más allá de sus propias especificidades, se enfrentaron a la misma disyuntiva que según Sigal (1991: 200-227) se les presentó a los intelectuales de izquierda a lo largo de la década del 60: el respeto a la ley marxista o la adopción de la identidad politica obrera.

En este sentido, podria entenderse entonces la "peronización" de las FAR como una opción eminentemente política y signo de un momento en que la corriente revolucionaria del peronismo estaba precisamente aflorando como nunca antes en su historia. Teniendo como antecedente más remoto la fundación del Partido Socialista de la Revolución Nacional en 1953, la izquierda peronista empezó a superar su debilidad intrínseca recién a mediados del 60 por medio de un proceso de acumulación de fuerzas y del surgimiento de experiencias autónomas, que llevaron luego del Cordobazo a que las organizaciones político-militares desplegaran un protagonismo creciente en el seno de esa corriente. El posicionamiento de las FAR puede interpretarse entonces como reflejo y apuesta de una

29. FAR y Montoneros, "Apoyar, defender y controlar" [24 de mayo de 1973], Baschetti (1996: 49-51). 
organización que en ese momento optó por el crecimiento y los objetivos decididamente revolucionarios de los sectores que en ese momento empezaron a dar forma a la "tendencia" (Gil, 1989: 48-82; Fraschini, 2008: 153-168).

En base a esas consideraciones, la confluencia con Montoneros, que se expresó primero por medio de un acercamiento de posiciones en torno a una postura "tendencista" respecto del peronismo para derivar en la fusión con dicha organización en octubre de 1973, puede ser vista como el último peldaño del proceso de "peronización" de las FAR en la medida que culminó con la decisión de integrar la organización que a fines de 1972 pasó a hegemonizar de forma decisiva ese sector revolucionario del peronismo en expansión. La fusión de ambas organizaciones que supuso el fin de la existencia de las FAR en cuanto tales es un tema que aún no ha sido abordado por ningún trabajo específico y que merece un análisis que supere las mutuas recriminaciones exculpatorias cruzadas por parte de ex militantes de diverso origen para explicar el devenir político de Montoneros a partir de 1973. Al respecto, seria interesante contrastar por medio de alguna investigación concreta las referencias genéricas presentes en la bibliografia existente que tienden a destacar tanto la homogeneidad resultante (Lewinger y Chaves, 1999; Flaskamp, 2002) como la existencia de diferencias de origen que no llegaron a sintetizarse en la nueva organización (Mero, 1987; Amorín, 2005).

La "peronización" de las FAR es sin dudas una referencia insoslayable en la trayectoria política de la organización, dada la importancia que tuvo para el devenir de ésta y porque históricamente se convirtió en una de las marcas distintivas de la misma. En este trabajo, hemos efectuado una primera aproximación al fenómeno, partiendo principalmente del discurso que la propia organización elaboró, aspecto necesario y que además ha sido contrastado con la polémica respecto del peronismo que tuvieron las FAR con el PRT-ERP. Esto sin dudas enriquece y complejiza la aprehensión del fenómeno al confrontar la postura de la propia organización en el tiempo y respecto de otro actor situado en el mismo contexto. Sin embargo, como establecimos, la "peronización" de las FAR no fue exclusivamente una definición teórica, si bien su argumentación se sostuvo en conceptualizaciones teóricas e ideológicas. Como ha sido reconocido por González Canosa (2012), la decisión de "peronizarse" de las FAR remitió a una apuesta política, que debemos destacar se produjo en un determinado momento y fue afectada sin dudas por un contexto tan cambiante como el de los albores de los 70. Precisamente, la interrelación entre el contexto y la construcción política de la organización es algo que parece ser dejado en segundo plano en su tesis en desmedro de un análisis que tiende a centrarse más en las elaboraciones políticoideológicas que en su práctica política concreta (ya sea armada y no 
armada). En un sentido global, la historización de la trayectoria política de las FAR para escapar a un excesivo "internismo" debería tratar de decirnos no solo lo que la organización sostenía que hacía, sino además también intentar dilucidar lo que efectivamente hizo, por medio de su relación con la visión que tenían otros actores y la situación contextual con la que interactuaba, siendo condicionada por ésta mientras tendía con su accionar a incidir en ella para su transformación.

\section{Bibliografia}

Amorín, José (2005), Montoneros: la buena historia, Buenos Aires: Catálogos. Baschetti, Roberto (comp.) (1995), Documentos 1970-1973. De la guerrilla peronista al gobierno popular, La Plata: De la Campana.

- (comp.) (1996), Documentos, 1973-1976. De Cámpora a la ruptura, vol. I, La Plata: De la Campana.

Cano, Diego (2011), “¿Estrategia foquista? La estructura politica argentina en la estrategia de revolución de Ernesto Guevara. Notas preliminares”, Izquierdas, $\mathrm{n}^{\circ} 11$, Santiago de Chile, pp. 70-87.

Caviasca, Guillermo (2006), Dos caminos. ERP-Montoneros en los setenta, Buenos Aires: Centro Cultural de la Cooperación, 2006.

Flaskamp, Carlos (2002), Testimonio de la lucha armada en Argentina (19681976), Buenos Aires: Nuevos Tiempos.

Fraschini, Mariano (2008), El brazo izquierdo de Perón. Ideólogos y actores de la izquierda peronista (1955-1974), Buenos Aires: Álvarez Castillo.

Furtak, Robert (1985), "Cuba: un cuarto de siglo de politica exterior revolucionaria”, Foro Internacional, vol. 5, no 4, México, pp. 343-361.

Gil, Germán Roberto (1989), La izquierda peronista (1955-1974), Buenos Aires: CEAL.

González Canosa, Mora (2012), Las Fuerzas Armadas Revolucionaras. Origenes y desarrollo de una particular conjunción entre marxismo, peronismo y lucha armada (1960-1973), tesis doctoral, Universidad Nacional de La Plata.

- (2013), “En las vísperas: debates y tensiones previas a la 'peronización' de las Fuerzas Armadas Revolucionarias (1970)", Lucha Armada, Anuario, Buenos Aires, pp. 40-57.

Guevara, Ernesto (1973a), "La guerra de guerrillas" [1960], Obras completas, tomo 2, Buenos Aires: Cepe, pp. 23-109.

- (1973b), "Guerra de guerrillas: un método" [1963], Obras completas, Tomo 3, Buenos Aires: Cepe, pp. 19-31.

Hernández Arregui, Juan José (1960), La formación de la conciencia nacional, Buenos Aires: Hachea.

Lanusse, Lucas (2005), Montoneros. El mito de sus doce fundadores, Buenos Aires: Vergara. 
Lewinger, Jorge Omar y Gonzalo Leónidas Chaves (1999), Los del 73, La Plata: De la Campana.

Mao Tse Tsung (1972), Sobre la guerra prolongada [1938], Buenos Aires: Cepe.

Mero, Roberto (1987), Conversaciones con Juan Gelman, Buenos Aires: Contrapunto.

Perón, Juan Domingo y John William Cooke (1972), Correspondencia, tomo II, Buenos Aires: Papiro.

Rodríguez Ostria, Gustavo (2006), Sin tiempo para las palabras. Teoponte: la otra guerrilla guevarista, Cochabamba: Kipus.

Sigal, Silvia (1991), Intelectuales y poder en la década del sesenta, Buenos Aires: Puntosur.

$$
* * *
$$

Titulo: From "Che" to Perón: about the "peronization" of the FAR

Resumen: Este artículo tiene como objeto analizar la "peronización" de las Fuerzas Armadas Revolucionarias (FAR), organización de origen marxista y cuyos principales líderes intentaron participar del proyecto guerrillero continentalista y de corte rural impulsado por Ernesto Guevara en Bolivia. Ante el fracaso de éste, dichos militantes redefinieron su estrategia revolucionaria, hecho que los llevó a conformar las FAR que aparecen públicamente en 1970 como una organización armada urbana. Rápidamente asumieron el peronismo como su identidad política reconociéndola como la experiencia de la clase obrera argentina y como medio de dotar de efectividad a su estrategia revolucionaria, fenómeno que llevó a un acercamiento con los otros sectores revolucionarios peronistas y que culminó con la fusión dentro de la organización Montoneros en 1973.

Palabras clave: FAR - Montoneros - peronismo - lucha armada

Summary: This article aims to analize the "peronization" of the Revolutionary Armed Forces (FAR), organization which origin was marxist and whose mains leaders tried to participate in the continentalist and rural project of guerrilla warfare led by Ernesto Guevara in Bolivia. Given the failure of Guevara's project, these militants redefined their revolutionary strategy and formed FAR, which apparead publicly in 1970 as an urban armed organization. Then, FAR assumed quickly peronism as his political identity reconigzing as the main experiencie of the argentine working class and as a way of giving effectiveness to their revolutionary strategy. These vision of Peronism led FAR to a rapprochement with others peronist revolutionary sectors, a process that culminated in the merger within the organization Montoneros in 1973.

Keywords: FAR - Montoneros - peronism - armed struggle

Recepción: 24 de mayo de 2016. Aprobación: 28 de julio de 2016. 